УДК 342.9

DOI https://doi.org/10.17308/vsu.proc.law.2020.3/2981

\title{
КАТЕГОРИРОВАНИЕ ПОДКОНТРОЛЬНЫХ ЛИЦ КАК УСЛОВИЕ ВЫБОРОЧНОСТИ ГОСУДАРСТВЕННОГО КОНТРОЛЯ И НАДЗОРА
}

\author{
С. А. Агамагомедова \\ Пензенский государственный университет \\ Поступила в редакцию 9 января 2020 г.
}

\begin{abstract}
Аннотация: исследуется категорирование приленительно к объектал контрольно-надзорной деятельности. Категорирование подконтрольных субъектов расслатривается как условие выборочности и достаточности государственного контроля и надзора. Делается вывод о тол, что категорирование подконтрольных лии присуще систеле государственного контроля и надзора достаточно давно. В условиях реборль контрольно-надзорной деятельности она приобретает новый уровень, обусловленный необходимостью выбора объекта и уровня контрольно-надзорного воздействия в иелях эконолии государственных ресурсов. Дифбберенииаиия подконтрольных лии используется и при профбилактике нарушений как приоритетной составляющей совреленной систель государственного контроля и надзора. С учетол того, что категорирование подконтрольных лии осуществляется на основе уровня риска, дается анализ критериев, характеризуюших уровень риска причинения вреда охраняельлм законол иенностял. В качестве условий успешного использования категорирования выделены: регулярная переоценка рисков; возложность для перехода подконтрольньх лии из одной категории в другую; учет состояния сфберь контрольно-надзорного воздействия. В качестве проблел категорирования подконтрольных лии при реализаиии государственного контроля и надзора названы отсутствие систелной связи рефборль контрольно-надзорной деятельности и работы по оптилизации норл КоАП РФ, а также недостаточный учет фбактора экономической интеграиии.

Ключевые слова: государственный контроль и надзор, уровень риска, выборочность и достаточность, категорирование подконтрольных лии, добросовестность, рефборла государственного контроля и надзора, административная ответственность.
\end{abstract}

\begin{abstract}
: the article examines the categorization in relation to the objects of control and supervision activities. The categorization of controlled entities is considered as a condition of selectivity and sufficiency of state control and supervision. It is concluded that the categorization of controlled persons has been inherent in the system of state control and supervision for a long time. In the context of the reform of control and oversight activities, it acquires a new level due to the need to select an object and the level of control and oversight impact in order to save state resources. Differentiation of controlled persons is also used in the prevention of violations as a priority component of the modern system of state control and supervision. Given that the categorization of controlled persons is carried out on the basis of the level of risk, an analysis of the criteria characterizing the level of risk of harm to the values protected by
\end{abstract}

(C) Агамагомедова С. А., 2020 


\section{Вестник ВГУ. Серия: Право}

law is given. The conditions for the successful use of categorization are: regular risk reassessment; the ability to transfer controlled entities from one category to another; accounting for the state of the sphere of control and supervisory impact. The problems of categorizing controlled entities during the implementation of state control and supervision include the lack of a systemic connection between the reform of control and supervision activities and the work on optimizing the norms of the Code of Administrative Offenses of the Russian Federation, as well as insufficient consideration of the economic integration factor.

Key words: state control and supervision, risk level, selectivity and sufficiency, categorization of controlled persons, good faith, reform of state control and supervision, administrative responsibility.

В течение последних лет система государственного контроля и надзора существенно реформируется. Государственный контроль и надзор трансформируется в направлении более системного административно-процедурного обеспечения, усиления позитивной (регулирующей) составляющей, автоматизации и цифровизации, снижения контрольно-надзорного давления на подконтрольную сферу. Последнее обеспечивается в том числе выборочностью государственного контроля и надзора. Выборочность становится одним из принципов контрольно-надзорной деятельности органов исполнительной власти, содержанием которого является возможность выбора контролирующим органом объекта контроля и надзора, уровень (меру) подобного контроля и надзора, выражающийся в определенной форме, периодичности применения мер контрольно-надзорного воздействия. Принцип выборочности государственного контроля и надзора тесно связан с принципом его достаточности. Последний заключается в использовании такого уровня контрольно-надзорного воздействия, который является достаточным (минимально необходимым, оптимальным) для обеспечения целей государственного контроля и надзора. Рассматриваемый принцип также связан с принципом соразмерности административной деятельности, закрепленным в законодательстве об административных процедурах отдельных иностранных государств ${ }^{1}$. Принцип достаточности государственного контроля и надзора предполагает отсутствие «избыточности» применительно к контролю и надзору как функциям государственного управления. При этом характеристика

168 «избыточность» справедливо отождествляется учеными с «излишеством» и «ненужностью»². С нашей точки зрения, «избыточность» в рассматриваемом аспекте можно трактовать и как «бесполезность».

Принципы выборочности и достаточности применительно к контрольно-надзорной деятельности органов исполнительной власти выступают,

${ }^{1}$ См.: Старилов Ю. Н., Давыљов К. В. Административная реформа в Российской Федерации на современном этапе : основные достижения, проблемы и перспективы // Правовая наука и реформа юридического образования. 2011. № 1 (24). C. 126.

${ }^{2}$ См.: Мартынов А. В., Ляпин И. Ф. К вопросу о понятии избыточных функций государственного управления // Вестник Нижегородского ун-та имени Н. И. Лобачевского. 2016. № 3. С. 148. 
на наш взгляд, отражением тенденции экономии государственного воздействия на определенные сферы общественных отношений, перехода к «умному» контролю, направленность которого носит более точечный характер, что в конечном итоге стимулирует әффективность как самого государственного контроля и надзора, так и всей системы государственного управления. Последняя в условиях реформы приобретает вектор позитивного, регулирующего правоприменения, стимулирующего определенные характеристики конкретной сферы социального взаимодействия. В этих условиях, по справедливому замечанию Ю. А. Тихомирова, традиционная «запретительно-наказательная» составляющая административного права явно теряет свое значение ${ }^{3}$ и уступает место регулятивному управленческому воздействию на отношения между гражданами и организациями и публичной властью.

Категоризация подконтрольных государственным органам лиц была присуща системе государственного контроля и надзора практически всегда. Речь идет, на наш взгляд, об универсальной дифференциации или дифференциации первого уровня, когда разновидность государственного контроля и надзора зависит от категории, организационно-правового или социально-экономического статуса лица, взаимодействующего с публичной властью.

Так, в зависимости от статуса налогоплательщика, его прав и обязанностей зависит перечень возможных контрольно-надзорных мероприятий, форм воздействия (требований) со стороны налогового органа. В зависимости от статуса лица, перемещающего товары через таможенную границу (гражданин, юридическое лицо или индивидуальный предприниматель), будут диффреренцироваться меры контрольно-надзорного воздействия со стороны таможенных органов (к примеру, порядок исчисления и взимания таможенных платежей). Наличие статуса резидента или нерезидента принципиально разграничивает направленность и содержание валютного контроля со стороны органов, его осуществляющих.

Полагаем, что в данном случае можно говорить о направлениях (или подвидах) конкретных видов государственного контроля и надзора (налогового, таможенного, валютного и др.).

Реформа контрольно-надзорной деятельности в стране привела к жизни качественно новую дифференциацию подконтрольных лиц (дифференциация второго уровня). По целому ряду критериев разграничиваются подконтрольные лица, относящиеся к одному статусу и подлежащие конкретному виду контрольно-надзорного воздействия. Данная категоризация в практике государственного контроля и надзора не нова. Так, еще с 2004 г. (с момента действия Таможенного кодекса РФ 2003 г.) при реализации таможенного контроля использовались специальные упрощенные процедуры (СУП) применительно к отдельным категориям подконтрольных лиц. Согласно ст. 68 Таможенного кодекса РФ 2003 г.

${ }^{3}$ См.: Тихолиров Ю. А. Публично-правовое регулирование : динамика сфер и методов // Журнал рос. права. 2001. № 5. С. 7. 


\section{Вестник ВГУ. Серия: Право}

критериями для отнесения подконтрольных лиц к категории лиц, имеющих право использовать СУП, являлись: отсутствие вступивших в силу и неисполненных постановлений по делам об административных правонарушениях в области таможенного дела, предусмотренных рядом статей главы 16 КоАП РФ; ведение лицом системы учета своей коммерческой документации в соответствующем порядке (установленном контролирующим органом); стаж осуществления внешнеэкономической деятельности (не менее трех лет) ${ }^{4}$.

С 2010 г. СУП получили развитие в институте уполномоченного экономического оператора (УЭО), закрепленном в Таможенном кодексе Таможенного союза (ст. 38-41) и позволяющем юридическим лицам пользоваться специальными упрощениями при совершении таможенных операций и прохождении таможенного контроля 5 .

С 1 января 2018 г. институт УЭО совершенствуется в направлении дальнейшей категоризации: Таможенный кодекс Евразийского экономического союза (ТК ЕАЭС) выделяет три категории УЭО, в зависимости от полученного статуса данные юридические лица вправе пользоваться определенным набором упрощений (глава 61$)^{6}$. ФТС России ведет реестр УЭО, контролирует включение юридических лиц в данный реестр, исключение лиц из него. Статус экономического оператора широко применяется в зарубежной практике (в частности в Европейском союзе) и, безусловно, является отражением доверия к бизнесу со стороны государства, которое предлагает снизить контрольно-надзорное воздействие в отношении отдельных категорий лиц в зависимости от определенных характеристик контролируемой деятельности. Последние в большинстве случаев в качестве критериев категорирования устанавливаются самим федеральным органом исполнительной власти, уполномоченным в соответствующей сфрере регулирования.

В условиях реформы государственного контроля и надзора категорирование подконтрольных лиц осуществляется на основе уровня риска, т. е. в зависимости от уровня риска (класса опасности) подконтрольные лица подразделяются на категории. От последней зависит уровень, форма, периодичность и иные характеристики государственного контроля и надзора.

При этом отметим, что в большинстве случаев на основе уровня риска подконтрольные лица подразделяются и к ним применяется выборочный

${ }^{4}$ Таможенный кодекс Российской Федерации : федер. закон от 28 мая 2003 г. № 61-ФЗ (с изм. от 23.12.2003) (утратил силу) // Рос. газета. 2003. 3 июня.

5 Таможенный кодекс Таможенного союза (ред. от 08.05.2015) (приложение к Договору о Таможенном кодексе Таможенного союза, принятому Решением Межгосударственного Совета ЕврАзЭС на уровне глав государств от 27.11.2009 № 17) (утратил силу) // Собр. законодательства Рос. Федерации. 2010. № 50. Ст. 6615.

${ }_{6}^{6}$ Таможенный кодекс Евразийского экономического союза (приложение № 1 к Договору о Таможенном кодексе Евразийского экономического союза) // Официальный сайт Евразийского экономического союза. URL: http://www.eaeunion.org/ (дата обращения: 12.12.2020). 
контроль, с учетом их категории, в отдельных случаях подконтрольные лица сначала получают определенный статус (дифференцируются), а уже на основе полученного статуса относятся к определенной категории риска. Так, в соответствии с п. 3 ст. 430 ТК ЕАЭС с момента вступления в силу свидетельства о включении в реестр УЭО данное юридическое лицо относится к категории низкого уровня риска?

Отражением выборочности контрольно-надзорной деятельности является и дифрференциация подконтрольных лиц при профилактике нарушений как важной составляющей современной системы государственного контроля и надзора. Так, с учетом базового положения систем профилактики контрольно-надзорных органов, реализующих профилактические меры на определенном уровне зрелости, для достижения ведомственной системой профилактики нарушений обязательных требований более высокого уровня зрелости контрольно-надзорный орган предпринимает меры, среди которых диффреренцирование подконтрольных субъектов по категориям риска (классам опасности), видам и характеристикам осуществляемой ими деятельности, используемым ими производственным объектам и иным параметрам, влияющим на риск причинения вреда охраняемым законом ценностям, включая критерий добросовестности подконтрольных субъектов ${ }^{8}$.

Данное категорирование имеет целью конкретизацию адресной направленности применяемых контрольно-надзорным органом профилактических мер, более полного охвата ими подконтрольной сферы.

В качестве критериев, характеризующих уровень риска причинения вреда охраняемым законом ценностям, могут выступать самые разные показатели подконтрольной деятельности, связанные с периодом ее осуществления, положительной или отрицательной ее динамикой, объемами и характером деятельности, статусом подконтрольного лица, его контрольно-надзорной и юрисдикционной историей, спецификой производимых товаров и оказываемых услуг и др.

Так, среди 30 критериев, характеризующих участников внешнеэкономической деятельности и установленных в целях распределения их по категориям уровней риска, есть такие, как размер уставного капитала; общий период осуществления внешнеэкономической деятельности; специализация по номенклатуре товаров; наличие фактов привлечения к административной ответственности; сумма назначенных административных штрафов; экспортная ориентированность подконтрольного лица ${ }^{9}$.

\footnotetext{
${ }^{7}$ Там же.

8 Стандарт комплексной профилактики нарушений обязательных требований : утв. Протоколом заседания проектного комитета по основному направлению стратегического развития Российской Федерации «Рефрорма контрольной и надзорной деятельности» от 12 сентября 2017 г. № 61(11). Документ опубликован не был. Доступ из справ.-правовой системы «КонсультантПлюс».

9 Об утверждении Порядка автоматизированного определения категории уровня риска участников внешнеэкономической деятельности : приказ ФТС Рос-
} 


\section{Вестник ВГУ. Серия: Право}

Интересно, что ряд критериев тесно связан с налоговым статусом подконтрольных лиц: наличие задолженности (недоимки) в соответствии с законодательством РФ о налогах и сборах; отнесение к низкому уровню налогового риска по результатам категорирования ФНС России. Это свидетельствует об определенной унификации и универсализации контрольно-надзорной деятельности органов исполнительной власти. Универсализация государственного контроля и надзора проявляется также в том, что одни контрольные мероприятия выступают мерами, обеспечивающими проведение различных видов государственного контроля (к примеру, налогового и таможенного $)^{10}$.

Что касается критерия добросовестности подконтрольных лиц, который часто упоминается в документах, обеспечивающих проведение редормы контрольно-надзорной деятельности, то он, на наш взгляд, требует отдельного рассмотрения. Полагаем, что добросовестность в публичной сфере вообще и при реализации государственного контроля и надзора в частности требует принципиальных доктринальных подходов, способных диффреренцировать ее от традиционного понимания добросовестности, присущего сфере частного права и развитого с точки зрения его институтов.

Анализ действующей нормативно-правовой и ведомственной базы осуществления реформы государственного контроля и надзора свидетельствует о том, что в качестве объектов для отнесения к конкретной категории риска или классу опасности выступают:

1) деятельность лиц (юридических лиц и индивидуальных предпринимателей);

2) используемые данными лицами производственные объекты.

При этом для определенного вида государственного контроля (надзора) применяются конкретные, разработанные соответствующим ведомством категории риска либо классы опасности ${ }^{11}$.

Содержание последних обусловлено, прежде всего, совокупностью охраняемых законом ценностей, на защиту которых направлена реализация соответствующих контрольно-надзорных полномочий. Для каждого вида государственного контроля и надзора должна быть определена конкретная комбинация ценностей. Именно комбинация, а не перечень,

сии от 1 декабря 2016 г. № 2256 (в ред. от 20.12.2019) // Таможенные ведомости. 2017. № 3 .

${ }^{10}$ См.: Агалаголедова С. А. Инвентаризация как мера, обеспечивающая проведение государственного контроля // Хозяйство и право. 2019. № 12. С. 103-109.

${ }^{11} \mathrm{O}$ применении риск-ориентированного подхода при организации отдельных видов государственного контроля (надзора) и внесении изменений в некоторые акты Правительства Российской Федерации (вместе с «Правилами отнесения деятельности юридических лиц и индивидуальных предпринимателей и (или) используемых ими производственных объектов к определенной категории риска или определенному классу (категории) опасности») : постановление Правительства РФ от 17 августа 2016 г. № 806 (в ред. от 21.03.2019) // Собр. законодательства Рос. Федерации. 2016. № 35. Ст. 5326. 


\section{Административное право и процесс}

так как в каждой сфере контрольно-надзорного воздействия сочетаются и нередко пересекаются различные ценности частного и публичного свойства.

При этом применительно к отдельным видам государственного контроля и надзора достаточно сложно установить единицы (критерии) и их количественное измерение, с помощью которых фиксируется объем причиненного вреда, в том числе нематериального характера ${ }^{12}$. Кроме того, помимо количественных показателей причиненного вреда в качестве критериев оценки контрольно-надзорной деятельности должны выступать параметры удовлетворенности подконтрольных лиц и иных субъектов контролируемой области социального взаимодействия состоянием данной области, а также критерии оптимизации и улучшения этого состояния по результатам контрольно-надзорного воздействия.

Обязательными условиями категорирования подконтрольных лиц при осуществлении государственного контроля и надзора являются: периодическая переоценка рисков, базирующаяся на изменении источников и фракторов риска для охраняемых законом ценностей; открытые и доступные «лифрты» для перехода подконтрольных лиц из одной категории в другую (из категории высокого риска в категорию низкого риска); учет на постоянной основе состояния сферы контрольно-надзорного воздействия, в том числе в соотношении со смежными областями государственного регулирования.

В качестве проблем категорирования подконтрольных лиц как условия выборочности и, как следствие, экономичности государственного контроля и надзора выделим следующие.

Одной из существенных, на наш взгляд, проблем в рассматриваемой области является необходимость синхронизации реформы контрольно-надзорной деятельности и совершенствования юрисдикционной деятельности контролирующих органов. Ученые справедливо констатируют, что без оптимизации норм КоАП РФ цели реформирования управленческого процесса не достижимы, и предлагают устанавливать административную ответственность за нарушение не только процедур предоставления государственных услуг, но и процедур исполнения государственных функций, важнейшими из которых являются контрольно-надзорные ${ }^{13}$.

Другим аспектом данной проблемы является то, что категорирование существует и при реализации государственного контроля и надзора, и

12 Базовая модель определения критериев и категорий риска : утв. протоколом заседания проектного комитета от 31 марта 2017 г. № 19(3) (вместе с «Требованиями к обоснованию предлагаемых федеральными органами исполнительной власти - участниками приоритетной программы «Реформа контрольной и надзорной деятельности» категорий риска (классов опасности) и критериев риска в отношении осуществляемых ими видов государственного контроля (надзора)»). Документ опубликован не был. Доступ из справ.-правовой системы «КонсультантПлюс».

${ }^{13}$ См.: Старилов Ю. Н., Давыљов К. В. Административная реформа в Российской Федерации на современном этапе : основные достижения, проблемы и перспективы. С. 139. 
при привлечении к административной ответственности по результатам контрольно-надзорной деятельности, однако критерии подобных разновидностей дифференциации невластных субъектов в большинстве случаев не сопрягаются.

В условиях экономической интеграции в рамках Евразийского экономического союза (ЕАЭС) остро встает проблема резидентства при осуществлении таможенного и иных видов государственного контроля и надзора в ЕАЭС. Формирующееся единое экономическое пространство требует унифицированных контрольно-надзорных механизмов, применяемых в экономической сфере. Несмотря на существенные сдвиги в области формирования единых принципов и инструментов контроля и надзора в рамках ЕАЭС, критерии категорирования подконтрольных субъектов при прохождении контроля и надзора в государствах - членах ЕАЭС отличаются, так же как и меры административной ответственности за нарушения в рассматриваемой сфере, что ставит хозяйствующих субъектов из разных государств - членов евразийской интеграции в неравные условия с точки зрения экономических прав и возможностей, свободы конкуренции.

Таким образом, категорирование подконтрольных лиц выступает условием выборочности и достаточности государственного контроля и надзора, в условиях реформы данное условие способствует снижению административной нагрузки на подконтрольную сферу.

Категорирование исторически присуще контрольно-надзорной деятельности государства, при этом в условиях реформы можно говорить о новом его уровне (дифференциация второго уровня), когда на категории делятся субъекты с равным административно-правовым (контрольно-надзорным) статусом в целях точечной направленности контрольно-надзорного воздействия.

В условиях реформы государственного контроля и надзора категорирование подконтрольных лиц осуществляется на основе уровня риска, причем оно присуще и деятельности по профилактике нарушений как составляющей системы государственного контроля и надзора.

В качестве объектов для отнесения к конкретной категории риска или классу опасности (которые одновременно позиционируются в качестве объектов государственного контроля и надзора) выступают деятельность подконтрольных лиц и (или) используемые ими производственные объекты.

Обязательными условиями эффективности категорирования подконтрольных лиц являются: периодическая переоценка рисков; доступная возможность для перехода подконтрольных лиц из одной категории в другую; учет на постоянной основе состояния сферы контрольно-надзорного воздействия.

В качестве проблем категорирования подконтрольных лиц как условия выборочности государственного контроля и надзора следует отметить отсутствие административно-процедурной согласованности реформы контрольно-надзорной деятельности с оптимизацией норм КоАП РФ, а 
также недостаточный учет фактора экономической интеграции. Решение их лежит в плоскости наднационального (интеграционного) механизма выборочности контроля и надзора, обеспеченного в части юрисдикционной составляющей контрольно-надзорной деятельности.

\author{
Пензенский государственный универ- \\ cumem
}

Агалаголедова С. А., кандидат юридических наук, доцент кафбедры государственно-правовых дисииплин

E-mail: saniyat_aga@mail.ru

\section{Penza State University}

Agamagomedova S. A., Candidate of Legal Sciences, Associate Professor of the State Legal Disciplines Department

E-mail: saniyat_aga@mail.ru 